Article

\title{
Promoting Consumer Engagement in Online Communities through Virtual Experience and Social Identity
}

\author{
Yu-Wei Chuang \\ Department of Computer Science and Information Management, Providence University, Taichung City 43301, \\ Taiwan; ywchuang@gm.pu.edu.tw; Tel.: +886-4-2632-8001
}

Received: 31 December 2019; Accepted: 21 January 2020; Published: 23 January 2020

check for updates

\begin{abstract}
With the development and proliferation of online games, understanding how to seize these players has become an essential issue for academic scholars and practitioners. Based on virtual experience in online gaming communities and consumer engagement perspectives, this research developed and verified a multi-dimensional framework for assessing how to retain and encourage players continuous dedication and engagement behaviors. The proposed framework illustrates the interrelationships among six constructs in online gaming communities: social presence, telepresence, cognitive social identity, affective social identity, psychological engagement, and behavioral engagement. Data collected from 338 players who have experience in engagement behaviors in online gaming communities. The collected data were examined against the research framework using structural equation modeling (SEM). The research findings offer sufficient evidence that behavioral engagement is influenced by psychological engagement, which consecutively, are determined by cognitive social identity, affective social identity, social presence, and telepresence. More importantly, the mediating analysis indicated that psychological engagement is a crucial mediator, meaning that consumer engagement is a sequential process, and behavioral engagement cannot independently exist without psychological engagement. Taken together, the research results of this study have several critical theoretical and practical implications for future academic researchers and practitioners to have better understanding of consumer engagement. By doing so, the game companies can have sustainable competitive advantage and support sustainable development.
\end{abstract}

Keywords: social presence; telepresence; cognitive social identity; affective social identity; consumer engagement

\section{Introduction}

The development of online games is becoming popular and is flourishing. The game companies continue to launch new ideas and innovative games, such as World of Warcraft, Legend of League, Hearthstone and so on. Players can interact or compete with other players in their virtual avatars in online games [1,2]. In recent years, massively multiplayer online games (MMOGs) have been attractive and players around the world have become highly attached to them. Players can build their own team with friends or people from all sides and play against other players' teams [3].

With the rapid development of information technology (IT) and artificial intelligence (AI), knowledge sharing and knowledge transfer in the network are getting faster and farther. The emerging technology such as AI can help companies discover, categorize, and share knowledge that contains valuable big data [4]. More specifically, AI can aid to transform big data into useful information and required knowledge required for companies to develop correct marketing and decision-making for sales strategies [5-7]. Therefore, the companies expect AI can help in customization, user personalization, 
product innovation, and reinforced marketing performance and readiness. On the other hand, people who have similar traits or interests gather in the virtual space of the internet. There are many kinds of discussion platforms. For example, online discussion forum (e.g., Mobile 01, PTT), social networking sites (e.g., Facebook), or online game discussion platforms (e.g., Bahamut, Gamebase, and online discussion space of game companies). Players share game information, exchange game experience, and use cyberspace to convey their thoughts and feedback about the games, which is similar to face-to-face communication between people in the real world. In general, this behavior is a kind of consumer engagement. Consequently, companies should use these emerging digital technologies to understand consumers' thought and to provide appropriate products or services to them.

With the advancements of IT and changes in time, the marketing strategy of enterprises needs to make substantial adjustments to satisfy consumers' needs. Consumers become more proactive and have the courage to express their opinions, ideas, and even complaints. Accordingly, companies must pay more attention to the voices of consumers than before and fulfill the needs of different consumers for the products of companies.

The traditional marketing strategy has been redefined under the rapid changes of time and technological advancements. Consumers are no longer passive, but they are more energetic in expressing their ideas, suggestions, and complaints. Consumer engagement hence has a considerable influence on the relationships between enterprises and consumers. Consequently, companies have responsibilities to listen carefully to the advice of consumers and to satisfy the needs of various consumers.

With the emergence of digital technology and the popularity of the Internet, surfing the Internet is becoming a part of personal life so that consumers can conveniently express their opinions. As reported by the International Telecommunications Union in 2017, the percentage of individuals using the Internet in Taiwan is $92.78 \%$, indicating that there are over 21.86 million people who had experience in using the Internet in Taiwan. In this investigation, the first top three countries/regions are Kuwait, Bermuda, as well as Iceland, and Taiwan is ranked 21st among 229 countries/regions. In East Asia, Taiwan is only behind the Republic of Korea. Another investigation proposed by Market Intelligence and Consulting Institute (MIC) of Taiwan in 2018 indicates that the most popular Internet services include video streaming, social media, instant messaging, online game, and online shopping. The usage of social media accounts for $80.6 \%$; hence, it can be seen that online interactive mechanisms such as social networking sites have profoundly affected people's daily lives and become an important tool for interpersonal interaction. This investigation further illustrated that consumers prefer to express opinions in social media as well as online discussion communities, and about $89.1 \%$ of consumers are influenced by electronic word-of-mouth when they make purchasing decisions. If companies can understand the consumer's perception of the products as well as services through social media, they can use consumer engagement behavior to help the improvement of their products and services to better meet the needs of consumers. By doing so, the sales revenue and market share will be increased.

Game players (consumers) can quickly and conveniently interact with other players and game operators (companies) through various community discussion spaces, online forums, and other communication channels. The game companies themselves can also use these channels to effectively interact with players and establish a good interactive relationship [8] to improve their games and reinforce the competitive advantage of firms. In the prior research of consumer engagement, scholars found that consumers were involved in the process of services or products to a certain degree. For example, consumers might mention their preferences so that the service providers can devote to meet consumers' needs. From the consumer's point of view, consumer engagement creates value for the consumer, and antecedent research also found that consumer engagement can increase the productivity of the organization and enhance the value of the consumer relationship [9]. However, related research in consumer engagement in the online game scenario is limited.

Additionally, researchers who studied online games mainly analyzed the motivation and feelings for playing online games as well as engagement behaviors in online gaming communities [10-12], whereas another research path focused on the negative effects of online game, such as game 
addiction [13], time distortion [14], menticide [15,16], and cheating behaviors in online gaming communities $[17,18]$. Nevertheless, antecedent research has rarely taken the positive effects of the online game into consideration [19]; therefore, this study will adopt the perspective of online game players' consumer engagement behavior. Moreover, the analysis unit of this research is used as an individual perspective to analyze whether online game players have social identity and consumer engagement behavior through their virtual experience (social presence and telepresence).

Taken together, when investigating consumer engagement in the online game, it is necessary to ponder not only the impact of virtual presence but also how the different kinds of social identity influence consumer engagement consecutively under the perspective of the team. As a result, this research takes social presence, telepresence, social identity as research themes to discuss the effect of consumer engagement.

The remainder of this study is organized as follows. The next section reviews the literature on consumer engagement, social presence, telepresence, cognitive social identity, and affective social identity. The research framework and hypotheses are later proposed depending on prior literature. The characterization of the constructed measures and data collection process is described in Section 3. Next, the data analysis results are illustrated. Ultimately, the practical implications and suggestions for future research are presented.

\section{Theoretical Background and Hypothesis Development}

This research seeks to cultivate a better comprehension of the relationships of social presence, telepresence, cognitive social identity, affective social identity, and psychological engagement, to behavioral engagement in the context of online gaming communities. On the basis of prior research, this section conceptualizes the constructs and develops the hypotheses for the research framework shown in Figure 1. This research model assumes that virtual experiences (social presence and telepresence) influence social identity dimensions (cognitive and affective social identity) and that social identity dimensions influence consumer engagement (psychological and behavioral engagement).

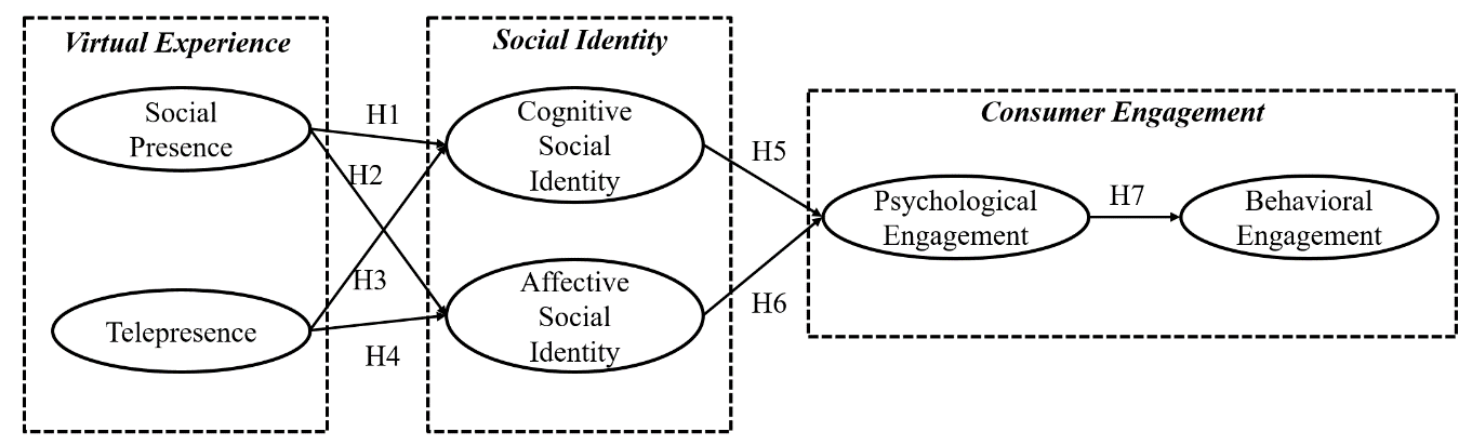

Figure 1. Research model.

\subsection{Online Game}

With high-speed internet becoming more prevalent throughout the world, online games are becoming the most popular form of entertainment and leisure among young people [10]. Online games are virtual worlds where players need to $\log$ in to the server and use their own PC to select virtual characters in this game through the Internet. They then interact with or compete with other players and accumulate experience as well as collect virtual treasures $[1,2]$. The classification of online games can be divided into console games and online games. The former indicates that the games can only be run on one PC and the latter that the games can be played on multiple computers via the Internet simultaneously $[1,20]$. The revenue models of online games are the pay-to-play mode and the free-to-play mode accompanied of advertisement interference. The pay-to-play mode means that 
the players must purchase the game software or game points to access the game. On the other hand, the free-to-play mode of the online game has been a great competitor to the pay-to-play mode [20].

\subsection{Massive Multiplayer Online Role-Playing Games}

The massive multiplayer online role-playing games (MMORPGs) are unique video game types that offer 2D or 3D high-sensitivity graphics, and players can create their own virtual avatars in massively multiplayer online games. Players can not only control their characters in the game and design the scenes they want but also interact with the characters of other players. Previously, MMORPGs research found some unique features, such as virtual avatar, virtual identity, co-existence, and group identity. These characteristics may trigger the player's learning and intimate behavior in the game [21]. Players include various characters from the virtual world [3], where players can create and control their own virtual avatars, and engage in the game with other players. In such places, players might be allies or have rival relationships with each other [22], and this offers players a wide variety of gameplays and options that allow players to interact with other players in the virtual world. This form of games can encourage different kinds of ages, ethnic groups, and professions to spend an average of $20 \mathrm{~h}$ a week in online games $[10,23,24]$.

Characteristic of MMORPGs are the places where players can present themselves as an avatar and hide their real identity. Through cyberspace, players can engage in various activities, such as play the games, interact with other players, and purchase virtual goods. Furthermore, players can change their relevant personal information such as gender, age, and appearance [10] in the online space of MMORPGs, meaning that players can create a desired virtual world to embark on whatever they want. There are many games, such as World of Warcraft, The Elder Scrolls Online, Final Fantasy XIV: A Realm Reborn, Star Wars: The Old Republic, Guild Wars 2, that can fulfill the desire of players' self-expression to attain enjoyment and satisfaction.

The functions of MMORPGs can be divided into two categories: competition and community. In terms of the competitive part, the game has strict rules and standards for players to measure the degree of achievement accomplished and to compare the characters' capability level between players. The opposite part is community interaction, which means that players interact and communicate with each other to develop an equal and harmonious community consciousness. The players then have a sense of belonging to the virtual community and members.

However, the studies of online games analyzed the characteristics [23,25-27], motivations [10], attitudes and feelings about online games [14], cognitive influence [28], online game addiction [27,29], and psychological harm $[15,16]$, but the literature on consumer engagement behavior is quite rare, which is the reason why this research pays attention to it.

\subsection{Virtual Experience}

In an online environment, social presence and telepresence are called virtual experience and coexistence [30,31]. Social presence is defined as the extent to which a mechanism allows people to create interpersonal relationships with others and facilitate people to sense others' psychological states. As suggested by Steuer [32], telepresence refers to the experience of appearing to be present in a distant environment via digital technology as communication channel.

\subsubsection{Social Presence}

The sense of presence refers to the sensation of being there with other people simultaneously. In other words, presence is a perception of being there in the same surroundings [33]. Individuals not only are aware of some degree of coexistence and presence [34] but also interact with others [35]. Furthermore, individuals can observe others' cognitive and psychological state via communicating with other entities [34].

Social presence is derived from the sense of presence. The social presence is defined in various ways. Short et al. [35] proposed the social presence theory. They said that social presence involves 
a considerable interpersonal communication between people. Using different social media causes varying degrees of social presence. As a result, some social networking sites emphasize engagement, and intercommunication activities can reinforce the feeling of social presence [36]. For example, when people login into social media, they can continue to keep track of offline friends by seeing their latest activities (i.e., story and post on Instagram) and make some comments on these activities. Salnääs et al. [37] showed that the meaning of social presence is the interaction between individuals through social media to make them feel like they are keeping together. Some researchers argued that social presence was an alternative manner of face-to-face communication [34].

As to the extent of social presence, a higher degree of social presence occurs in face-to-face interactions between people. Conversely, ways of communication such as emails or written letters have a lower sense of social presence. In modern times, while individuals have a higher social presence on the chosen social media, they not only engage and continue to use the chosen social media but also encourage their friends to use the same social media. Social presence can establish an interpersonal relationship and emotional bonding through interaction. When people perceive warm, social, and sensitive feelings, they seem to understand the psychological states of others even though their interaction is based on social media. Individuals perceive the positive or negative feeling from the intercommunication in the online virtual communities. When people perceive a positive feeling, they dedicate themselves more to the activities in the virtual space and generate a sense of virtual reality. Once people are completely absorbed in the environment, social presence and telepresence are generated [36,38].

In online gaming communities, players use an anonymous avatar to interact and communicate with other players. The sense of social presence helps other people develop their sense of common consciousness and interpersonal relationship. Accordingly, people perceiving higher social presence would, in turn, have positive feelings towards other players and continue interacting with them [36]. Shen et al. [39] suggested that members with higher common consciousness make the virtual community easier to develop and sustain. Additionally, they also indicated that the higher common consciousness is related to social identity. Social presence means the sense of mutual understanding so that the members have strong motivation to recognize the commonalities with other members and cultivate social identity in virtual communities. Therefore, this study proposes Hypothesis 1 :

\section{Hypothesis 1. (H1) Social presence positively affects cognitive social identity.}

The individual can feel free to show themselves in front of other members; the mutual trust is thus developed. When people trust and feel the existence of other members, the emotional connection with each other and the value of this relationship are built [40]. Rice [41] said that people transmit and express their emotional signals to their closed members more easily when they have a higher sense of social presence. Shen et al. [39] suggested that members with higher social presence are likely to develop social relationships and create an affective social identity in virtual communities. Therefore, this research poses Hypothesis 2:

Hypothesis 2. (H2) Social presence positively affects affective social identity.

\subsubsection{Telepresence}

Another virtual experience in virtual communities is telepresence. Steuer [32] argued that telepresence was an experience of environmental presence through information technology, resulting from the actual distance between people decreasing in the virtual environment. The original concept of telepresence uses IT or social media to realize the virtual reality, depicting the scenario where people feel like they exist in that virtual place [32,41]. Walker and Sheppard [42] suggested that telepresence can generate a feeling of being there, regardless of space or distance limitations. 
Telepresence has long been used to explore the inter-relationships such as the perception of time distortion, enjoyment, and higher presence in the virtual environment [43]. In the research of telepresence, interactivity and vividness play important roles, meaning that people can receive reciprocal responses immediately in the virtual environment. The higher the level of telepresence, the higher the interactive and realistic feelings occurring in the virtual space [41,44]. For example, when appearances of the virtual space are highly interactive and vivid, the sense of telepresence is strengthened. Furthermore, different degrees of telepresence have different influence. If the individual is fully immersed in a high-telepresence environment, he or she focuses on who they are communicating with and intendedly have a positive intercommunication. In the same vein, while people have a higher sense of telepresence, they are more likely to trust each other and have communication.

From a business point of view, telepresence can bring marketing benefits, for example, consumers can perceive detailed information about a specific product through the official website of enterprises. The positive belief and attitude toward the product are thus formed [41]. Fiore et al. [44] said that telepresence makes consumers feel they are personally on the scene, providing the illusion of a virtual space. Accordingly, the sense of telepresence affects the consumers' attitude and purchase intention.

When an individual is absorbed in a high-telepresence environment, he or she focuses on the people who interact with himself or herself and realizes their existence with each other. The positive interaction is important to build an emotional connection under the telepresence environment. While people perceive high-telepresence in the virtual world, positive social value is generated, which includes the feeling of being accepted, giving a good impression to others, and others appreciating one's argument [36]. Accordingly, people devote their minds to being involved in this online community and interacting with other members. Therefore, this study presents the hypothesis 3 :

Hypothesis 3. (H3) Telepresence positively affects cognitive social identity.

Telepresence can lead to a strong emotional connection and response, allowing people to completely immerse themselves in the virtual environment, despite distance and space constraints $[45,46]$. When people have emotional attachment to members and virtual communities, the high degree of emotional value (i.e., enjoyment and pleasure) is thus produced. Therefore, this study proposes hypothesis 4:

Hypothesis 4. (H4) Telepresence positively affects affective cognitive identity.

\subsection{Social Identity}

Turner [47] stated that identification is an individual's self-concept, which is group-based and includes ideas, feelings, and behaviors. Additionally, Bagozzi and Dholakia [48] analyzed the effects of interpersonal and inter-group relationships, including social responsibility, internalization (the consistency between individuals and members' values or goals), and different types of social identity. Social identity is also the most frequently referred to in the discussion of identity [49]. Social identity means the common feeling, thought, and sense generated by people in the personal network or the virtual community in the online network [50].

Turner [51] indicated that social identity can make individuals share their common characteristics with other members in the group, rather than want to reveal their own distinctive features. Tajfel and Turner [52] also mentioned that social identity theory contains three essential elements: the self-awareness of membership, the sense of belonging of the group, and the value of self-assessment to the group [53]. Furthermore, Tajfel and Turner [52] suggested that individual self-awareness within the group and the significant emotional connection between group members can generate a sense of social identity. Hogg and Abrams [54] said that social identity can make each member cultivate group identity and become aware of an individual being a part of this group; hence, the sense of belonging to this group is developed. 
Related research also indicated that social identity can be used to describe the behavioral interests of group members. For example, it was found that social identity affects favoritism within a group formation experiment [53]. Bergami and Bagozzi [55] conducted a survey of the employees of a food service company and found that social identity affects organizational citizenship behavior. Moreover, Algesheimer et al. [56] found that the members engage in the activities of a car club, as a result of social identity. Social identity theory can also be used to explain the contribution of each member in the group and then reinforce the cohesiveness of this group [48]. Furthermore, Ellemers et al. [53] proposed that social identity theory can be divided into distinct types, such as the cognitive aspect of social identity and the affective aspect of social identity.

\subsubsection{Cognitive Social Identity}

Cheung and Lee [57] said that cognitive social identity was a self-categorization process, which allows the individual to be conceptually interchangeable with other group members and conceptually different from outsiders. In other words, the self-categorization process demonstrated that the individual has the cognitive awareness of one's group membership and is distinguished from the emotional commitment to the group. In the self-categorization process, an individual compares the similarities between self and other group members and then emphasizes the differences with outsiders based on their self-perception and observation [58]. When individuals perceive a degree of similarity between their own characteristics and other group members' characteristics, the sense of group identity and group membership are developed. Thus, the possibility of participating in group activities is increased [59].

\subsubsection{Affective Social Identity}

In addition to cognitive social identity, social identity also includes the emotional aspect. Cheung and Lee [57] indicated that affective social identity referred to the degree of emotional participation of a group. The characteristics of affective social identity are the group participation and the emotional attachment to the group. In the organization setting, the affective social identity represents the emotional bonding with the group members and the members' identity with the goals and values of the organization.

Ellemers et al. [53] said that affective social identity is also an affective commitment, which means the degree of participation in the activities of the group. Affective commitment is defined as the degree of embeddedness between the members in the organization, the members' empathy for the organization, and the members' recognition of the organization's goals and values. Affective commitment includes the following factors: social identity, self-esteem, stability, confidence, security, and belonging [60-62].

Previous studies have also found that affective social identity brings about some behaviors, such as favoritism. In the experiment of group formation, researchers found that affective social identity influences the nepotism of group members [53]. On the contrary, affective social identity has positive effects on marketing research. Meyer et al. [63] proved that affective social identity positively influences loyalty and promotes an individual's self-presence in the group [63]. Furthermore, affective social identity can be used to answer why consumers have the willingness to keep the buyer-supplier relationship in a stable and solid status. Meanwhile, affective social identity further entails emotional attachment and sense of belonging. In the brand community, affective social identity enhances the intimacy of behavior between brands and consumers to attain a harmonious relationship [56]. Affective social identity is an emotional expression based on psychological state. When members have higher affective social identity with other members of the group, they will have higher motivations for community engagement.

Both cognitive and affective social identity are essential to the development of the group. This results from social identity being generated from self-concept and then affecting social intentions and behaviors. Consequently, when an individual perceives a strong social identity, the higher 
social intention is cultivated. Bhattacharya and Sen [64] observed that when emotional commitment toward the group increased, the extent of connection and interdependence among members also grew. Such behaviors promote the sustainable development of the group. Regarding the members of virtual communities, a great deal of emotional commitment induces members to help each other, constantly providing advice, information, and offering constructive suggestions [65]. In the consumer engagement part, Kumar et al. [66] argued that regardless of whether the transaction is concluded or not, the interaction between the client and enterprise or other consumers can be referred to as consumer engagement. Van Doorn et al. [8] suggested that consumer engagement not only occurs in trading behavior but also mainly focuses on the interaction between the enterprise and the consumer. Specifically, consumer engagement implies that the consumer is driven by a certain motivation to engage in behavior such as word-of-mouth behavior, providing advice, writing reviews on blogs for a specific brand or enterprise. Moreover, the aforementioned interactive activities positively affect psychological engagement [67]. Based on the research of the above scholars, this study proposes hypotheses 5 and 6 :

Hypothesis 5. (H5) Cognitive social identity positively affects psychological engagement.

Hypothesis 6. (H6) Affective social identity positively affects psychological engagement.

\subsection{Consumer Engagement}

In the globally competitive and rapidly changing business environment, product innovation is an important approach to acquire competitive advantages. Innovative product means that enterprises can seize the market trend and meet consumers' requirements, which in turn raises the profits and increases the sustainable competitive edge. Ullah et al. [68] indicated that compared to the average revenue of consumers, the high engagement consumers have more than 23 percent profits and long-term relationships. In the above discussion, the importance of consumer engagement is self-evident.

Abbas et al. [69] stated that consumer engagement is a psychological status since it is an extensive notion than simply accounts for particular behaviors. Chan et al. [9] argued that consumer engagement refers to the individual's perception, emotion, and emotional representation of the brand in the online discussion community. Similarly, Hollebeek et al. [70] stated that consumer engagement is the evaluation of perception, emotion, and behavior when consumers interact with other consumers or brands. Cheung et al. [67] investigated consumer engagement in the online game context, which can be divided into two aspects: psychological engagement (i.e., psychological process) and behavioral engagement (i.e., behavioral manifestation). Cheung et al. [67] further illustrated that psychological engagement includes three elements: vigor, absorption, and dedication: (i) vigor means the energy and psychological resilience of the consumer; (ii) absorption indicates the degree to which consumers are attentive; (iii) dedication refers to the extent of consumers' feeling of significance, incentive, and encouragement toward the specific entity. Fang et al. [71] also have the same perspective of psychological engagement. However, they defined behavioral engagement as individual continuous interaction with a specific entity. As discussed above, consumer engagement is a complex and multi-dimensional notion [72,73]. Therefore, Cheung et al. [67] divided consumer engagement into psychological engagement and behavioral engagement in the online game scenario. Moreover, psychological engagement is believed to cause behavioral engagement [67,71], such as actively participating in the activities of online gaming communities, supporting other members, and recommending this community to others. If players have willingness to put their effort into this online gaming community, they will be more likely to increase their frequency and strength of online gaming community participation. Taken together, this study refers to Cheung et al. [67] and Fang et al. [71] for the definition of consumer engagement. 
Recently, some studies also put forward similar arguments that psychological engagement should positively influence behavioral engagement in mobile apps [71], in online game sales [67], or in brand virtual communities [73]. Therefore, this study proposes hypotheses 7 :

Hypothesis 7. (H7) Psychological engagement positively affects behavioral engagement.

\section{Methods}

\subsection{Measures of the Constructs}

As suggested by Bohmstedt [74], the selected measurement items of research must embody the construct and derive from the literature to make sure the content validity of the measures. Consequently, to assure face validity and content validity, all measurement items in this research were pre-tested by an expert panel of MMORPGs and adapted from previous research, with minor changes in the wording so that to conform to the context of this study of online gaming communities. Concretely, the scale for social presence was adapted from $\mathrm{Wu}$ et al. [20] and the scale for telepresence was adapted from Shang et al. [36]. The scales of affective social identity and cognitive social identity were adapted from Cheung and Lee [57]. Finally, psychological consumer engagement and behavioral consumer engagement measures were adapted from Fang et al. [71]. The seven-point Likert scales with anchors ranging from "strongly disagree" to "strongly agree" (ranging from 1 to 7) were used for all measurement items. The measurement items are listed in Appendix A.

\subsection{Data Collection}

On account of this research intended to investigate the relationships among virtual experience (social presence and telepresence), social identity factors, and consumer engagement behaviors in the context of online gaming communities, targeted respondents included those who had online communication experience. Data used to verify the research framework was collected from an online convenience sample in Taiwan from March to May 2018. The online investigation was uploaded to a survey portal (i.e., https://zh.surveymonkey.com/) in Taiwan that every Internet user could access. Initially, the questionnaire was posted on the PTT bulletin board system. PTT in the largest and most popular online discussion forum in Taiwan since 1995. At present, the total number of registered users in PTT is more than 1.5 million. During the peak hours, more than 150,000 users are online. Subsequently, respondents were asked whether they had ever used online gaming communities. Only participants who had experience in using online gaming communities could attempt the rest of the online investigation. The investigation asked that participants reminisce about their most visited online gaming communities. Then, participants were instructed to reply to all questions based on their experience in using this online gaming community. For each question, participants were requested to select the answer that best depicted their level of agreement. The first round yielded 202 effective responses, and the second round yielded an additional 136 responses. In total, the investigation received 338 valid responses and consisted of 270 males and 68 females. The majority of respondents were aged between 21 and 29 (61.5 percent), while nearly 90.8\% had at least a college degree, revealing that the participants were primarily young and educated. The respondents who had played online games for over four years accounted for 73.7 percent; 5.6 percent had played for 3-4 years; 5.6 percent had played for $2-3$ years, and 15.1 percent had played online games for under 2 years. Furthermore, a chi-square analysis of the demographic data of the respondents showed no difference from the demographic data of all the respondents used in the survey. This suggested no non-response bias in the returned questionnaires. The demographic profiles of the respondents are shown in Table 1. 
Table 1. Respondent characteristics $(n=338)$.

\begin{tabular}{|c|c|c|c|c|c|c|}
\hline Characteristic & Items & Frequency & Percentage & Chi-Square & DF & $p$-Value \\
\hline \multirow{2}{*}{ Gender } & Male & 270 & $79.9 \%$ & \multirow{2}{*}{1.648} & \multirow[b]{2}{*}{1} & \multirow{2}{*}{0.199} \\
\hline & Female & 68 & $20.1 \%$ & & & \\
\hline \multirow{4}{*}{ Age } & 19 or below & 19 & $5.6 \%$ & \multirow{4}{*}{1.128} & \multirow{4}{*}{3} & \multirow{4}{*}{0.770} \\
\hline & $20-29$ & 208 & $61.5 \%$ & & & \\
\hline & $30-39$ & 107 & $31.7 \%$ & & & \\
\hline & 40 or above & 4 & $1.2 \%$ & & & \\
\hline \multirow{3}{*}{$\begin{array}{l}\text { Educational } \\
\text { Background }\end{array}$} & High School and under & 31 & $9.2 \%$ & \multirow{3}{*}{4.333} & \multirow{3}{*}{2} & \multirow{3}{*}{0.115} \\
\hline & Bachelor's degree & 248 & $73.3 \%$ & & & \\
\hline & Master's degree and over & 59 & $17.5 \%$ & & & \\
\hline \multirow{5}{*}{$\begin{array}{l}\text { Time spent on } \\
\text { average playing } \\
\text { this game per day }\end{array}$} & 1 hour or below & 7 & $2.1 \%$ & \multirow{5}{*}{1.776} & \multirow{5}{*}{4} & \multirow{5}{*}{0.777} \\
\hline & $1-2 \mathrm{~h}$ & 71 & $21 \%$ & & & \\
\hline & $3-4 h$ & 153 & $45.3 \%$ & & & \\
\hline & $5-6 h$ & 67 & $19.8 \%$ & & & \\
\hline & Over $6 \mathrm{~h}$ & 40 & $11.8 \%$ & & & \\
\hline \multirow{5}{*}{$\begin{array}{l}\text { Time since they } \\
\text { started to play } \\
\text { this game }\end{array}$} & 1 year or below & 25 & $7.4 \%$ & \multirow{5}{*}{3.899} & \multirow{5}{*}{4} & \multirow{5}{*}{0.420} \\
\hline & $1-2$ years & 26 & $7.7 \%$ & & & \\
\hline & $2-3$ years & 19 & $5.6 \%$ & & & \\
\hline & $3-4$ years & 19 & $5.6 \%$ & & & \\
\hline & Over 4 years & 249 & $73.7 \%$ & & & \\
\hline
\end{tabular}

\section{Results}

The core theme of this study is to analyze the causal relationship between social presence, telepresence, cognitive social identity, emotional social identity, and consumer engagement behavior in the online gaming communities as well as verify the overall fitness of the research model; hence, structural equation modeling (SEM) is used. SEM is a statistical technique used to verify the suitability of a theoretical model, which can simultaneously estimate the measurement indicators and potential variables in the model, not only to estimate the measurement error of the indicator variable in the measurement process but also to evaluate the reliability and validity.

SEM includes measurement model and structure model. Measurement mode analysis is used to illustrate the relationship between potential constructs and measured variables and to measure the reliability and validity. The structural model analysis illustrates the causal relationship of potential constructs and calculates the amount of explanatory and unexplained variation [75].

\subsection{Measurement Model}

IBM SPSS Amos 21.0 was used to conduct confirmatory factor analysis (CFA) to examine the measurement model. The whole model fit was evaluated by eight common goodness-of-fit indexes: the ratio of chi-square to degrees of freedom (chi-square/df), goodness of fit index (GFI), adjusted goodness of fit index (AGFI), non-normalized fit index (NNFI), comparative fit index (CFI), incremental fit index (IFI), relative fit index (RFI), and root mean square error of approximation (RMSEA). The results of these indexes, together with their recommended values for the overall model fit, are shown in Table 2. All the model-fit indexes surpassed recommended cut-off value suggested by antecedent studies [76], therefore, reporting that the measurement model illustrated a good model fit with the data gathered $($ chi-square $/ \mathrm{df}=2.064, \mathrm{GFI}=0.926, \mathrm{AGFI}=0.894, \mathrm{NNFI}=0.966, \mathrm{CFI}=0.973, \mathrm{IFI}=0.973$, RFI $=0.936$, RMSEA $=0.056$ ). Accordingly, the further analyses could be executed to assess the psychometric features of the measurement model such as individual item reliability, convergent validity, and discriminant validity. 
Table 2. Fit indexes for measurement and structural models.

\begin{tabular}{cccc}
\hline Fit Indices & Recommended Value & Measurement Model & Structural Model \\
\hline X2/df & $\leq 3.00$ & 2.064 & 2.639 \\
GFI & $\geq 0.90$ & 0.926 & 0.902 \\
AGFI & $\geq 0.80$ & 0.894 & 0.868 \\
NNFI & $\geq 0.90$ & 0.966 & 0.947 \\
CFI & $\geq 0.90$ & 0.973 & 0.956 \\
IFI & $\geq 0.90$ & 0.973 & 0.957 \\
RFI & $\geq 0.90$ & 0.936 & 0.918 \\
RMSEA & $\leq 0.08$ & 0.056 & 0.070 \\
\hline
\end{tabular}

Notes: AGFI: adjusted goodness-of-fit index; NNFI: non-normalized fit index; CFI: comparative fit index; IFI: incremental fit index; RFI: relative fit index; RMSEA: root mean square error of approximation.

As indicated in Table 3, the test of individual item reliability was evaluated by using factor loading, which should exceed 0.70 [76]. Convergent validity was assessed via composite reliability (CR) and average variance (AVE). As shown in Table 3, the CR of all constructs surpasses 0.8 , obviously higher than the cut-off level of 0.70. Meanwhile, the AVE of all constructs are also greater than the recommended value of 0.5 [77], indicating the adequacy of individual item reliability and convergent validity of the measurement model [76]. To examine discriminant validity, the comparisons of correlations between constructs with the square roots of AVE of each construct [78] were proceeded to verify it. As reported in Table 4, the correlations between constructs were lower than the square roots of AVE, meaning discriminant validity is confirmed. Taken together, the measurement model illustrated sufficient reliability, convergent validity, and discriminant validity.

Table 3. Factor loadings, CR and AVE.

\begin{tabular}{ccccc}
\hline Construct & Items & Factor Loading & CR & AVE \\
\hline \multirow{3}{*}{ Social Presence } & SP1 & $0.799^{* * *}$ & & \\
& SP2 & $0.811^{* * *}$ & 0.885 & 0.720 \\
& SP3 & $0.930^{* * *}$ & & \\
Telepresence & TP1 & $0.781^{* * *}$ & & \\
& TP2 & $0.881^{* * *}$ & 0.859 & 0.670 \\
& TP3 & $0.790^{* * *}$ & & \\
Cognitive Social Identity & CSI1 & $0.912^{* * *}$ & & \\
& CSI2 & $0.915^{* * *}$ & 0.926 & 0.807 \\
& CSI3 & $0.867^{* * *}$ & & \\
Affective Social Identity & ASI1 & $0.876^{* * *}$ & & \\
& ASI2 & $0.894^{* * *}$ & 0.925 & 0.804 \\
& ASI3 & $0.920^{* * *}$ & & \\
Psychological Engagement & PE1 & $0.892^{* * *}$ & & \\
& PE2 & $0.748^{* * *}$ & 0.889 & 0.728 \\
& PE3 & $0.911^{* * *}$ & & \\
Behavioral Engagement & BE1 & $0.894^{* * *}$ & & \\
& BE2 & $0.853^{* * *}$ & 0.919 & 0.791 \\
& BE3 & $0.919^{* * *}$ & &
\end{tabular}

Notes: 1. CR: Composite Reliability. 2. AVE: Average Variance Extracted values; ${ }^{* * *}$ denotes significance at $p<0.001$ respectively. 
Table 4. Reliability, average variance extracted, and discriminant validity.

\begin{tabular}{ccccccc}
\hline Construct & SP & TP & CSI & ASI & PE & BE \\
\hline SP & 0.849 & & & & & \\
TP & 0.312 & 0.819 & & & & \\
CSI & 0.461 & 0.422 & 0.898 & & & \\
ASI & 0.635 & 0.321 & 0.416 & 0.897 & & \\
PE & 0.584 & 0.349 & 0.492 & 0.505 & 0.853 & \\
BE & 0.560 & 0.170 & 0.354 & 0.370 & 0.594 & 0.889 \\
\hline
\end{tabular}

Notes: 1. SP: Social Presence; TP: Telepresence; CSI: Cognitive Social Identity; ASI: Affective Social Identity; PE: Psychological Engagement; BE: Behavioral Engagement. 2. Diagonal elements (grey background cells) are the square roots of the average variance extracted (AVE) values; off-diagonal elements are correlations among constructs.

\subsection{Common Method Bias}

Because the data were self-reported and collected from a single source, this study conducted the Harman's one-factor test to evaluate common method bias [79]. Four factors with eigenvalues greater than 1.0 (ranging from 1.34 to 8.09 ) emerged from the un-rotated factor solution with the principal component method. The total percentage of variance accounting for these four components is 74.32. In the meantime, the analysis results also indicate that the first component accounts for less than $50 \%$ of the total variance. Additionally, this study further conducted single-factor model to examine the effect of common method bias. The single-factor model led to $X^{2}(135)=2396.337$, compared with the measurement model $X^{2}(120)=247.693$, the measurement model is obviously superior to the single-factor model [80]. According to the results of these two analyses, the common method bias was not a problem in this study.

\subsection{Structural Model}

In the part of the structural model, the model fit was also examined and reported in Table X. The results indicate that all seven indexes for structural model (chi-square/df $=2.639, \mathrm{GFI}=0.902$, AGFI $=0.868, \mathrm{NNFI}=0.947, \mathrm{CFI}=0.956, \mathrm{IFI}=0.957, \mathrm{RFI}=0.918, \mathrm{RMSEA}=0.070)$ attained the acceptable level and suggested a good model fit, meaning that the structural model is appropriate for advanced statistical analysis in terms of hypotheses testing.

The results of hypotheses testing, path coefficients, $t$ values, and SMC values are described in Figure 2. As expected, all the hypothesized relationships are supported. Social presence and telepresence both had significant positive effects on cognitive social identity and affective social identity $(\gamma=0.378, p<0.001 ; \gamma=0.651, p<0.001 ; \gamma=0.337, p<0.05 ; \gamma=0.148, p<0.05$, respectively). Cognitive social identity and affective social identity both had significantly positive influences on psychological engagement $(\gamma=0.364, p<0.001 ; \gamma=0.418, p<0.001$, respectively). Finally, psychological engagement demonstrated significantly positive effect in affecting behavioral engagement $(\gamma=0.637, p<0.001)$. Overall, the research model explains $34.9 \%$ of the variance in cognitive social identity, $51.7 \%$ in affective social identity, $42.7 \%$ in psychological engagement, and $40.5 \%$ in behavioral engagement.

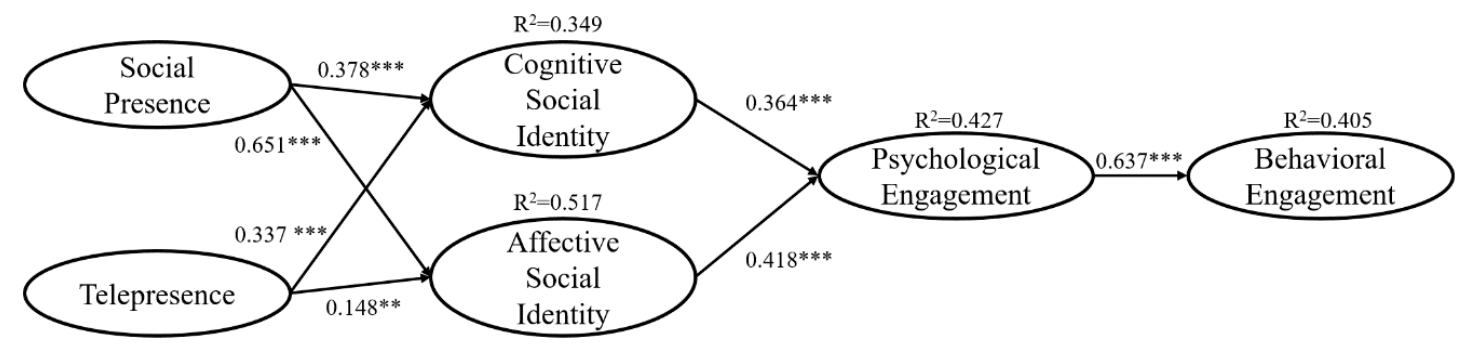

Figure 2. Hypothesis test results. (Note: ${ }^{*}{ }^{* *}$ and ${ }^{* * *}$ denote significance at $p<0.05, p<0.01$, and $p<0.001$ respectively.) 
It is notable that the direct and total effects of cognitive social identity and affective social identity on psychological engagement were 0.364 and 0.418 , respectively. Affective social identity demonstrated stronger direct and total effects on psychological engagement than cognitive social identity. Among the influences of virtual experience (social presence and telepresence) on cognitive social identity and affective social identity, the results indicate that social presence had stronger effects on cognitive social identity and affective social identity. Taken together, the summarized results are shown in Table 5.

Table 5. The direct, indirect, and total effect of variables depicted.

\begin{tabular}{ccccccccccccc}
\hline \multirow{2}{*}{ Effect } & \multicolumn{3}{c}{ Direct Effect } & \multicolumn{4}{c}{ Indirect Effect } & \multicolumn{4}{c}{ Total Effect } \\
\cline { 2 - 12 } & CSI & ASI & PE & BE & CSI & ASI & PE & BE & CSI & ASI & PE & BE \\
\hline SP & 0.378 & 0.651 & & & & & 0.409 & 0.261 & 0.378 & 0.651 & 0.409 & 0.261 \\
TP & 0.337 & 0.148 & & & & & 0.185 & 0.118 & 0.337 & 0.148 & 0.185 & 0.118 \\
CSI & & & 0.364 & & & & & 0.232 & & & 0.364 & 0.232 \\
ASI & & & 0.418 & & & & & 0.266 & & & 0.418 & 0.266 \\
PE & & & & 0.637 & & & & & & & & 0.637 \\
\hline
\end{tabular}

Notes: SP: Social Presence; TP: Telepresence; CSI: Cognitive Social Identity; ASI: Affective Social Identity; PF: Psychological Engagement; BE: Behavioral Engagement.

\section{Discussion}

Despite the flourishing growth in the online game market, limited studies have explored the interaction of related constructs in the online game and online gaming communities, including virtual experience (social presence and telepresence), social identity factors (cognitive social identity and affective social identity), as well as consumer engagement (psychological engagement and behavioral engagement). This research is devoted to filling the knowledge gap by establishing and verifying a theoretical framework of consumer engagement behaviors in online gaming communities that were found in the current literature on virtual experience, social identity, and consumer engagement. This research framework seized the multi-dimensional and the bilateral dependent essence of constructs determining the behaviors of online gaming communities. The empirical findings suggest that social presence, telepresence, cognitive social identity, affective social identity, psychological engagement, and behavioral engagement are valid measures of online gaming communities. All the hypotheses between the six success constructs are supported by the analytical results.

As reported by the results, several valuable implications can be addressed. In keeping with the proposed framework, psychological and behavioral engagement are more effective constructs of online gaming communities than the other four constructs. Psychological and behavioral engagement should be encouraged while the formation of social presence, telepresence, cognitive social identity, and affective social identity are well managed. Therefore, game companies ought to pay much attention to the advancement of virtual experience, social identity formation, and consumer engagement processes. For the purpose of increasing consumer engagement behavior of game players, the online game developers should not only provide a better online discussion space where game players can freely express their ideas and suggestions about the game but also encourage game players and game developers to have deeper reciprocal interactions and extensive opinion exchanges. By doing so, the game itself and game developers could continuously absorb the valuable advice as well as improve their products, thus building a bonding relationship. A successful game developer must be open-minded to accept the criticism and learn modestly from the suggestions from game players.

Cognitive social identity and affective social identity partially mediate the effects of social presence and telepresence on psychological engagement and behavioral engagement. Cognitive social identity and affective social identity continue to be essential determinants of psychological engagement and behavioral engagement. The findings also indicate that social presence has stronger direct and total effects on behavioral engagement via cognitive social identity, affective social identity, and psychological engagement (see Table 5), suggesting the importance of social presence in promoting affective social identity and of psychological engagement in strengthening behavioral engagement. 
Prior studies have proposed that psychological engagement has a positive effect on behavioral engagement [67,71]; however, they did not further examine the mediating effect of psychological engagement or its antecedent constructs. Accordingly, the mediating analysis is further conducted. To validate the mediating role of psychological engagement, this study followed the guidelines of Zhao et al. [81]. The result of mediating analysis is shown in Table 6. According to Zhao et al. [81], the statistical significance of indirect effects should be firstly verified, which means that the indirect effects of cognitive social identity and affective social identity on behavioral engagement via psychological engagement are both significant at $p<0.05$, and zero is not included in the $95 \%$ confidence interval. This study subsequently validates the significance of direct effects of cognitive social identity and affective social identity on behavioral engagement, with the mediator (psychological engagement) controlled to testify the type of mediation.

Table 6. The mediating effect analysis.

\begin{tabular}{cccccccc}
\hline \multirow{2}{*}{ Path } & \multirow{2}{*}{$\begin{array}{c}\text { Point } \\
\text { Estimates }\end{array}$} & \multicolumn{2}{c}{ Product of Coefficients } & \multicolumn{2}{c}{ Bias-Corrected CI } & \multicolumn{2}{c}{ Percentile CI } \\
\cline { 3 - 8 } & & SE & $\mathbf{Z}$ & Lower & Upper & Lower & Upper \\
\hline CSItoPEtoBE & 0.171 & 0.047 & 3.638 & 0.096 & 0.273 & 0.096 & 0.272 \\
ASItoPEtoBE & 0.192 & 0.047 & 4.085 & 0.115 & 0.310 & 0.109 & 0.292 \\
Direct Effect & 0.040 & 0.051 & 0.784 & -0.055 & 0.154 & -0.057 & 0.146 \\
$\quad$ (CSItoBE) & & & & & & & \\
Direct Effect & 0.088 & 0.071 & 1.239 & -0.043 & 0.231 & -0.046 & 0.230 \\
$\quad$ (ASItoBE) & 0.492 & 0.073 & 6.740 & 0.340 & 0.631 & 0.344 & 0.640 \\
\hline Total Indirect Effect & 0.494 &
\end{tabular}

Notes: CSI: Cognitive Social Identity; ASI: Affective Social Identity; PF: Psychological Engagement; BE: Behavioral Engagement.

As reported by Table 6, psychological engagement completely mediates the relationship between cognitive social identity and behavioral engagement as well as between affective social identity and behavioral engagement. The results indicate that the indirect-only relationships of cognitive social identity, affective social identity, and behavioral engagement exist, meaning that psychological engagement is fully mediated by the relationship between cognitive social identity and behavioral engagement as well as by the relationship between affective social identity and behavioral engagement. This means that consumer engagement is a sequential process, and behavioral engagement cannot independently exist without psychological engagement.

The empirical findings indicate the significance of a multi-dimensional way of evaluating online gaming communities. Scholars can gain from this framework by taking it as the fundamental basis to establish comprehensive measures of online gaming communities, investigate inter-relationships between the proposed success constructs, and contrast different frameworks of online gaming communities. The empirical results also stimulate game companies to take measures of social presence, telepresence, cognitive social identity, affective social identity, psychological engagement, as well as behavioral engagement into consideration when they design and evaluate a brand-new online game.

\section{Limitations and Future Research}

A strict research process was carried out to establish and examine the proposed framework; nonetheless, the empirical research has some limitations that can be considered in future research. Firstly, the study verified the limited users of online games (mainly WOW players) and a specific player group (Taiwan players). Accordingly, other online game types or player groups could be included to develop the robustness of the current research. Secondly, the use of self-reported data to examine the research components might raise the concern of common method bias; therefore, post hoc statistical analysis is required. The measurements of subjectivity and objectivity should be contained and scrutinized for their inter-relationships. With no doubt, a set of possible antecedent factors such as technological (i.e., interactivity and sociability), spatial (i.e., density and stability), and social (i.e., social capital and social exchange) factors may have an impact on social identity and consumer engagement. 
Future research could advance exploration of the influence of these factors. Additionally, future research could extend the proposed model and take different online games (i.e., Diablo and League of Legends) into consideration to compare their results is similar or not. Future research also can consider investigating the longitudinal data of a series of observations to avoid cross-sectional analysis approach. Consequently, the future researchers can design deeper research to understand the causal relationships and correlations between the constructs of online gaming communities.

\section{Conclusions}

\subsection{Theoretical Implications}

An important contribution of this research is the development a consumer engagement model of online gaming communities that goes beyond the concept of community continuance intention. As far as we know, this research is the first study to investigate virtual experience and social identity driving consumer engagement. This research theoretically revealed the relationships between virtual experience attributes, social identity characteristics, psychological engagement, and behavioral engagement and verified them empirically based on the context of online gaming communities.

The results of this research offer new insights into consumer engagement literature by exploring its antecedents in online gaming communities. Although previous studies explored consumer engagement in a mobile travel app and in the purchase of digital goods in an online game [68,72], no prior study has identified its antecedent factors under the scenario of online gaming communities. This research advances this knowledge basis by empirically identifying the two kinds of virtual experience as antecedents driving consumer engagement in online gaming communities. Furthermore, this research advances to prove that consumer engagement is a consecutive process and behavioral engagement cannot independently exist without psychological engagement.

\subsection{Managerial Implications}

This research provides some evidence to echo practitioners. Blizzard Entertainment is one of the biggest game companies in the world. In 2018, Blizzard launched a new game, Diablo Immortal, which is the first mobile game since Diablo, released to the game market in 1996. The game's promotional video received 250,000 dislikes less than one day since the chair game designer, Wyatt Cheng, announced the game on the annual festivity, BlizzCon 2018. For example, a hardcore fan of Blizzard, Dontinquire, said that he was very disappointed about this game and that this game should be cancelled. Moreover, many fans use the hashtags \#NotMyDiablo on social media and some Blizzard fan propose a petition on the social welfare petition website Change.org to express their anger and ask Blizzard to cancel this game. Their statement is as follows: "Blizzard does not care about the community anymore. This is an outrage and a spit on the face of the Diablo community. Sign this petition to show them how disappointed we are and hopefully help wake them up to see that they have lost sight of what their core fan base desires." Most of the fans criticize the playability, in-app purchase mechanism, the limitation of the mobile phone, the similarity with another game (i.e., Land of Glory), user interface (UI), and user experience (UX).

One year later, Blizzard announced that they will release a new PC game, Diablo IV, in the near future. In the meantime, the president of Blizzard, J. Allen Brack, said that he thought they did a poor job when they announced Diablo: Immortal. Additionally, Brack admitted that they did not communicate well with the players. He also said that they did not properly explain to their core fans that they did not want to abandon the PC platforms or switch to home consoles and mobile games.

From the example of Blizzard, we can conclude that the players' virtual experience in online games facilitates social identity formation in online gaming communities. When players feel strongly identified with the game and the game companies, they have strong and vigorous motivations to engage in online gaming communities psychologically. When events such as the one involving Diablo Immortal happen, the players present behavioral engagement, such as calling for support online and becoming 
cohesive to demand that the game company take some action in response to the players' requests and expectations.

Taken together, this research not only provides theoretical contribution to academic research but also offers powerful evidence to remind game companies must always take players' thought and feedback as their first priority. This study emboldens future researchers to continue investigating and validating the scenario in online gaming communities and provides more useful suggestions to practitioners.

Funding: This research was substantially supported by the Ministry of Science and Technology (MOST) of Taiwan under grant number MOST 106-2410-H-126-005 -.

Conflicts of Interest: The author declares no conflict of interest.

\section{Appendix A Measurements Scales (Strongly Disagree/Agree, 1-7 Scale)}

- $\quad$ Social Presence (adapted from [10])

- SP1 In my interactions with other members, I am able to be myself and show what kind of member/person I really am.

- SP2 I trust that other members in this online gaming community will help me if I need it.

- SP3 I feel connected to other players in this online gaming community.

- $\quad$ Telepresence (adapted from [23])

- TP1 Being in this online gaming community often makes me forget where I am

- TP2 After using this online gaming community, I feel like I come back to the "real world" after a journey.

- TP3 This online gaming community creates a new world for me, and this world suddenly disappears when I stop using it.

- Cognitive Social Identity (adapted from [45])

- CSI1 In this online gaming community, my personal identity and the identity of this community is similar to that of other members.

- CSI2 In this online gaming community, my self-image is similar to that of other members.

- CSI3 In this online gaming community, my perspective of online games is similar to that of other members.

- $\quad$ Affective Social Identity (adapted from [45])

- $\quad$ ASI1 I feel a strong sense of being part of this online gaming community.

- ASI2 I am very attached to this online gaming community.

- ASI3 I enjoy myself as a member of this online gaming community.

- Psychological Engagement (adapted from [60])

- PE1 I feel strong and vigorous when I am using this online gaming community.

- PE2 I am enthusiastic in this online gaming community.

- PE3 Using this online gaming community is absorbing and immersive.

- Behavioral Engagement (adapted from [60])

- BE1 I am willing to actively participate in the activities in this online gaming community.

- BE2 I am willing to support other members in this online gaming community.

- BE3 I will recommend this online gaming community to anyone seeking advice about online gaming communities. 


\section{References}

1. Kim, M.G.; Kim, J. Cross-validation of reliability, convergent and discriminant validity for the problematic online game use scale. Comput. Hum. Behav. 2010, 26, 389-398. [CrossRef]

2. Lo, S.; Wang, C.; Fang, W. Physical interpersonal relationships and social anxiety among online game players. Cyberpsychol. Behav. 2005, 8, 15-20. [CrossRef]

3. Chen, H.; Mori, Y.; Matsuba, I. Solving the balance problem of massively multiplayer online role-playing games using coevolutionary programming. Appl. Soft Comput. 2014, 18, 1-11. [CrossRef]

4. Codini, A.; Abbate, T.; Aquilani, B. Knowledge co-creation in open innovation digital platforms: Processes, tools and services abstract. J. Bus. Ind. Mark. 2019, 34, 1434-1447.

5. Paschen, J.; Kietzmann, J.; Kietzmann, T. Artificial intelligence (AI) and its implications for market knowledge in B2B marketing. J. Bus. Ind. Mark. 2019, 34, 1410-1419. [CrossRef]

6. Singh, J.; Flaherty, K.; Sohi, R.S.; Deeter-Schmelz, D.; Habel, J.; Le Meunier-FitzHugh, K.; Malshe, A.; Mullins, R.; Onyemah, V. Sales profession and professionals in the age of digitization and artificial intelligence technologies: Concepts, priorities, and questions. J. Pers. Sell. Sales Manag. 2019, 39, 1-21. [CrossRef]

7. Syam, N.; Sharma, A. Waiting for a sales renaissance in the fourth industrial revolution: Machine learning and artificial intelligence in sales research and practice. Ind. Mark. Manag. 2018, 69, 135-146. [CrossRef]

8. Verhoef, P.C.; Reinartz, W.I.; Krafft, M. Customer engagement behavior: Theoretical foundations and research directions. J. Serv. Res. 2010, 13, 247-252. [CrossRef]

9. Chan, T.K.H.; Zheng, X.; Cheung, C.M.K.; Lee, M.K.O.; Lee, Z.W.Y. Antecedents and consequences of customer engagement in online brand communities. J. Mark. Anal. 2014, 2, 81-97. [CrossRef]

10. Yee, N. The demographics, motivations and derived experiences of users of massively multi-user online graphical environment. Presence Teleoperators Virtual Environ. 2006, 15, 309-329. [CrossRef]

11. Ghazali, E.; Mutum, D.; Woon, M.Y. Multiple Sequential Mediation in an Extended Uses and Gratifications Model of Augmented Reality Game Pokémon Go. Internet Res. 2019, 29, 504-528. [CrossRef]

12. Kim, M.; Kim, J. The Effects of Perceived Online Justice on Relational Bonds and Engagement Intention: Evidence from an Online Game Community. Comput. Hum. Behav. 2018, 84, 410-419. [CrossRef]

13. King, D.L.; Kaptsis, D.; Delfabbro, P.H.; Gradisar, M. Craving for Internet games? Withdrawal symptoms from an 84-h abstinence from massively multiplayer online gaming. Comput. Hum. Behav. 2016, 62, 488-494. [CrossRef]

14. Hussain, Z.; Griffiths, M.D. The attitudes, feelings, and experiences of online gamers: A qualitative analysis. Cyberpsychol. Behav. 2009, 12, 747-753. [CrossRef] [PubMed]

15. Whitty, M.T.; Young, G.; Goodings, L. What I won't do in pixels: Examining the limits of taboo violation in MMORPGs. Comput. Hum. Behav. 2011, 27, 268-275. [CrossRef]

16. Young, G.; Whitty, M.T. Games without frontiers: On the moral and psychological implications of violating taboos within multi-player virtual spaces. Comput. Hum. Behav. 2010, 26, 1228-1236. [CrossRef]

17. Chen, V.H.H.; Wu, Y. Group identification as a mediator of the effect of players' anonymity on cheating in online games. Behav. Inf. Technol. 2015, 34, 658-667. [CrossRef]

18. Wu, Y.; Chen, V.H.H. Understanding Online Game Cheating: Unpacking the Ethical Dimension. Int. J. Hum. Comput. Interact. 2018, 34, 786-797. [CrossRef]

19. Ma, J.; Lu, Y.; Gupta, S. User innovation evaluation: Empirical evidence from an online game community. Decis. Support Syst. 2019, 117, 113-123. [CrossRef]

20. Wu, J.H.; Wang, S.C.; Tsai, H.H. Falling in love with online games: The uses and gratifications perspective. Comput. Hum. Behav. 2010, 26, 1862-1871. [CrossRef]

21. Kong, J.S.L.; Kwok, R.C.K.; Fang, Y. The effects of peer intrinsic and extrinsic motivation on MMOG game-based collaborative learning. Inf. Manag. 2012, 49, 1-9. [CrossRef]

22. Steinkuehler, C.; Williams, D. Where everybody knows your (screen) name: Online games as 'third laces'. J. Comput. Mediat. Commun. 2006, 11, 885-909. [CrossRef]

23. Griffiths, M.D.; Davies, M.N.O.; Chappell, D. Demographic factors and playing variables in online computer gaming. Cyberpsychol. Behav. 2004, 7, 479-487. [CrossRef] [PubMed]

24. Williams, D.; Yee, N.; Caplan, S. Who plays, how much, and why? A behavioral player census of virtual World. J. Comput. Mediat. Commun. 2008, 13, 993-1018. [CrossRef] 
25. Ducheneaut, N.; Yee, N.; Nickell, E.; Moore, R.J. The Life and Death of Online Gaming Communities: A Look at Guilds in World of Warcraft. In Proceedings of the SIGCHI Conference on Human Factors in Computing Systems, San Jose, CA, USA, 28 April-3 May 2007; ACM: San Jose, CA, USA, 2007; pp. 839-848.

26. Pittman, D.; Dickey, C.G. A Measurement Study of Virtual Populations in Massively Multiplayer Online Games. In Proceedings of the 6th ACM SIGCOMM Workshop on Network and System Support for Games, Melbourne, Australia, 19-20 September 2007; ACM: Melbourne, Australia, 2007; pp. 25-30.

27. Smahel, D.; Blinka, L.; Ledabyl, O. Playing MMORPGs: Connections between addiction and identifying with a character. Cyberpsychol. Behav. 2008, 11, 715-718. [CrossRef]

28. Bruno, C.D.S.; Leonardo, X.D.L.E.S.; Antonio, R. MMORPGS and cognitive performance. A study with 1280 Brazilian high school students. Comput. Hum. Behav. 2010, 26, 1564-1573.

29. Mehroof, M.; Griffiths, M. Online gaming addiction: The role of sensation seeking, self-Control, neuroticism, aggression, state anxiety, and trait anxiety. Cyberpsychol. Behav. 2009, 13, 1-4. [CrossRef]

30. Zhao, Y.; Wang, A.; Sun, Y. Technological environment, virtual experience, and MOOC continuance: A stimulus-organism-response perspective. Comput. Educ. 2020, 144, 103721. [CrossRef]

31. Animesh, A.; Pinsonneault, A.; Yang, S.B.; Oh, W. An Odyssey into Virtual Worlds: Exploring the Impacts of Technological and Spatial Environments on Intention to Purchase Virtual Products. MIS Q. 2011, 35, 789-810. [CrossRef]

32. Steuer, J. Defining virtual reality: Dimensions determining telepresence. J. Commun. 1992, 42, 73-93. [CrossRef]

33. Heeter, C. Being there: The subjective experience of presence. Presence Teleoperators Virtual Environ. 1992, 1, 262-271. [CrossRef]

34. Biocca, F.; Nowak, K. Plugging your body into the telecommunication system. In Communication Technology and Society; Lin, C., Atkin, D., Eds.; Hampton Press: Waverly Hill, VI, USA, 2001; pp. 407-447.

35. Short, J.A.; Williams, E.; Christie, B. The Social Psychology of Telecommunications; John Wiley \& Sons: New York, NY, USA, 1976.

36. Shang, R.A.; Chen, Y.C.; Huang, S.C. A private versus a public space: Anonymity and buying decorative symbolic goods for avatars in a virtual world. Comput. Hum. Behav. 2012, 28, 2227-2235. [CrossRef]

37. Sallnäs, E.-L. Effects of communication mode on social presence, virtual presence, and performance in collaborative virtual environments. Presence Teleoperators Virtual Environ. 2005, 14, 434-449. [CrossRef]

38. Gefen, D.; Straub, D.W. Consumer trust in B2C e-commerce and the importance of social presence: Experiments in e-products and e-services. Omega 2004, 32, 407-424. [CrossRef]

39. Shen, K.N.; Yu, A.Y.; Khalifa, M. Knowledge contribution in virtual communities: Accounting for multiple dimensions of social presence through social identity. Behav. Inf. Technol. 2010, 29, 337-348. [CrossRef]

40. Rice, R.E. Media appropriateness: Using social presence theory to compare traditional and new organizational media. Hum. Commun. Res. 1993, 19, 458-484. [CrossRef]

41. Suh, K.S.; Chang, S. User interfaces and consumer perceptions of online stores: The role of telepresence. Behav. Inf. Technol. 2006, 25, 99-113. [CrossRef]

42. Walker, G.R.; Sheppard, P.J. Telepresence-The future of telephony. BT Technol. J. 1997, 15, 11-18. [CrossRef]

43. Mahfouz, A.Y.; Philaretou, A.G.; Theocharous, A. Virtual social interactions: Evolutionary, social psychological and technological perspectives. Comput. Hum. Behav. 2008, 24, 3014-3026. [CrossRef]

44. Fiore, A.M.; Kim, J.; Lee, H.H. Effect of image interactivity technology on consumer responses toward the online retailer. J. Interact. Mark. 2005, 19, 38-53. [CrossRef]

45. Gerrig, R.J. Experiencing Narrative Worlds; Yale University Press: New Haven, CT, USA, 1993.

46. Kim, T.; Biocca, F. Telepresence via television: Two dimensions of telepresence may have different connections to memory and persuasion. J. Comput. Mediat. Commun. 1997, 3. [CrossRef]

47. Turner, J.C. Rediscovering the Social Group: A Self-Categorization Theory; Blackwell: Oxford, UK, 1987.

48. Bagozzi, R.P.; Dholakia, U.M. Intentional social action in virtual communities. J. Interact. Mark. 2002, 16, 2-21. [CrossRef]

49. Papadopoulos, T.; Stamati, T.; Nopparuch, P. Exploring the determinants of knowledge sharing via employee weblogs. Int. J. Inf. Manag. 2013, 33, 133-146. [CrossRef]

50. Bagozzi, R.P.; Dholakia, U.M. Open source software user communities: A study of participation in Linux user groups. Manag. Sci. 2006, 52, 1099-1115. [CrossRef] 
51. Turner, J.C. Towards a cognitive redefinition of the social group. In Social Identity and Intergroup Relations; Tajfel, H., Ed.; Cambridge University Press: Cambridge, UK, 1982; pp. 15-40.

52. Tajfel, H.; Turner, J.C. An integrative theory of intergroup conflict. In The Social Psychology of Intergroup Relations; Austin, W.G., Worchel, S., Eds.; Brooks/Cole: Monterey, CA, USA, 1979; pp. 33-47.

53. Ellemers, N.; Kortekaas, P.; Ouwerkerk, J. Self-categorisation, commitment to the group and group self-esteem as related but distinct aspects of social identity. Eur. J. Soc. Psychol. 1999, 29, 371-389. [CrossRef]

54. Hogg, M.A.; Abrams, D. Social Identifications: A Social Psychology of Intergroup Relations and Group Processes; Routledge: London, UK, 1988.

55. Bergami, M.; Bagozzi, R.P. Self-categorization, affective commitment and group self-esteem as distinct aspects of social identity in the organization. Br. J. Soc. Psychol. 2000, 39, 555-577. [CrossRef]

56. Algesheimer, R.; Dholakia, U.M.; Herrmann, A. The social influence of brand community: Evidence from German car clubs. J. Mark. 2005, 64, 19-34. [CrossRef]

57. Cheung, C.M.K.; Lee, M.K.O. A Theoretical Model of Intentional Social Action in Online Social Networks. Decis. Support Syst. 2010, 49, 24-30. [CrossRef]

58. Ashforth, B.E.; Mael, F.A. Social identity theory and the organization. Acad. Manag. Rev. 1989, 14, $20-39$. [CrossRef]

59. Terry, D.J.; Hogg, M.A.; White, K.M. The theory of planned behaviour: Self-identity, social identity and group norms. Br. J. Soc. Psychol. 1999, 38, 225-244. [CrossRef]

60. Hobfoll, S.E. Social and psychological resources and adaptation. Rev. Gen. Psychol. 2002, 6, 307-324. [CrossRef]

61. Lapointe, E.; Vandenberghe, C.; Panaccio, A. Organizational commitment, emotional exhaustion and turnover: A conservation of resources perspective. Hum. Relat. 2011, 64, 1609-1631. [CrossRef]

62. Schmidt, K.H. Organizational commitment: A further moderator in the relationship between work stress and strain? Int. J. Stress Manag. 2007, 14, 26-40. [CrossRef]

63. Meyer, J.P.; Stanley, D.J.; Herscovitch, L.; Topolnytsky, L. Affective, continuance, and normative commitment to the organization: A meta-analysis of antecedents, correlates, and consequences. J. Vocat. Behav. 2002, 61, 20-52. [CrossRef]

64. Bhattacharya, C.B.; Sen, S. Consumer-company identification: A framework for understanding consumers' relationships with companies. J. Mark. 2003, 67, 76-88. [CrossRef]

65. Tsai, H.T.; Pai, P. Why do newcomers participate in virtual communities? An integration of self-determination and relationship management theories. Decis. Support Syst. 2014, 57, 178-187. [CrossRef]

66. Kumar, V.; Aksoy, L.; Donkers, B.; Venkatesan, R.; Wiesel, T.; Tillmanns, S. Undervalued or overvalued customers: Capturing total customer engagement value. J. Serv. Res. 2010, 13, 297-310. [CrossRef]

67. Cheung, C.M.K.; Shen, X.-L.; Lee, Z.W.Y.; Chan, T.K.H. Promoting sales of online games through customer engagement. Electron. Commer. Res. Appl. 2015, 14, 241-250. [CrossRef]

68. Ullah, A.; Aimin, W.; Ahmed, M. Smart Automation, Customer Experience and Customer Engagement in Electric Vehicles. Sustainability 2018, 10, 1350. [CrossRef]

69. Abbas, M.; Gao, Y.; Shah, S.S.H. CSR and Customer Outcomes: The Mediating Role of Customer Engagement. Sustainability 2018, 10, 4243. [CrossRef]

70. Hollebeek, L.D.; Glynn, M.S.; Brodie, R.J. Consumer brand engagement in social media: Conceptualization, scale development and validation. J. Interact. Mark. 2014, 28, 149-165. [CrossRef]

71. Fang, J.; Zhao, Z.; Wen, C.; Wang, R. Design and performance attributes driving mobile travel application engagement. Int. J. Inf. Manag. 2017, 37, 269-283. [CrossRef]

72. Brodie, R.J.; Ilic, A.; Juric, B.; Hollebeek, L. Consumer engagement in a virtual brand community: An exploratory analysis. J. Bus. Res. 2013, 66, 105-114. [CrossRef]

73. De Vries, N.J.; Carlson, J. Examining the drivers and brand performance implications of customer engagement with brands in the social media environment. J. Brand Manag. 2014, 21, 495-515. [CrossRef]

74. Bohmstedt, G.W. Reliability and validity assessment in attitude measurement. In Attitude Measurement; Summers, G.F., Ed.; Rand-McNally: Chicago, IL, USA, 1970; pp. 80-99.

75. Jöreskog, K.G.; Sörbom, D. LISREL 8: Structural Equation Modeling with the SIMPLIS Command Language. In Scientific Software International; Lawrence Erlbaum Associates, Inc.: Mahwah, NJ, USA, 1993.

76. Hair, J.F., Jr.; Black, W.C.; Babin, B.J.; Anderson, R.E. Multivariate Data Analysis with Readings, 7th ed.; Pearson: London, UK, 2009. 
77. Henseler, J.; Ringle, C.M.; Sinkovics, R.R. The use of partial least squares path modeling in international marketing. In New Challenges to International Marketing (Advances in International Marketing; Sinkovics, R.R., Ghauri, P.N., Eds.; Emerald Group: Bingley, UK, 2009; Volume 20, pp. 277-319.

78. Fornell, C.; Larcker, D.F. Evaluating structural equation models with unobservable variables and measurement error. J. Mark. Res. 1981, 18, 39-50. [CrossRef]

79. Podsakoff, P.M.; MacKenzie, S.B.; Lee, J.Y.; Podsakoff, N.P. Common Method Biases in Behavioral Research: A Critical Review of the Literature and Recommended Remedies. J. Appl. Psychol. 2003, 88, 879-903. [CrossRef] [PubMed]

80. Chen, C.J.; Hung, S.W. To give or to receive? Factors influencing members' knowledge sharing and community promotion in professional virtual communities. Inf. Manag. 2010, 47, 226-236. [CrossRef]

81. Zhao, X.; Lynch, J.G.; Chen, Q. Reconsidering Baron and Kenny: Myths and Truths about Mediation Analysis. J. Consum. Res. 2010, 37, 197-206. [CrossRef]

(C) 2020 by the author. Licensee MDPI, Basel, Switzerland. This article is an open access article distributed under the terms and conditions of the Creative Commons Attribution (CC BY) license (http://creativecommons.org/licenses/by/4.0/). 